Article

\title{
Silica-functionalized $N$-propylpiperazine for immobilization of palladium nanoparticles as efficient heterogeneous catalyst for cyanation reactions
}

\author{
Khodabakhsh NIKNAM *, Abdollah DERIS, Farhad PANAHI \\ Department of Chemistry, Faculty of Sciences, Persian Gulf University, Bushehr 75169, Iran
}

\section{A R T I C L E I N F O}

\section{Article history:}

Received 30 September 2012

Accepted 18 December 2012

Published 20 April 2013

Keywords:

Palladium nanoparticle

Silica-bonded $N$-propylpiperazine

Cyanation reaction

Aryl halide

\begin{abstract}
A B S T R A C T
An efficient heterogeneous Pd catalytic system has been developed, based on immobilization of Pd nanoparticles (PNPs) on a silica-bonded $N$-propylpiperazine (SBNPP) substrate. The SBNPP substrate effectively stabilizes the PNPs and improves their stability against aggregation. The catalytic activity of this catalyst was investigated in the cyanation of aryl halides with $\mathrm{K}_{4}\left[\mathrm{Fe}(\mathrm{CN})_{6}\right]$ as the cyanide source. The catalyst could be recycled several times without appreciable loss of catalytic activity.
\end{abstract}

(C) 2013, Dalian Institute of Chemical Physics, Chinese Academy of Sciences. Published by Elsevier B.V. All rights reserved.

\section{Introduction}

Aryl nitriles are important building blocks of numerous pharmaceuticals, agrochemicals, herbicides, natural products, and dyes $[1,2]$. They are also valuable intermediates in organic synthesis and can be easily transformed into a range of heterocycles. In addition, nitriles are versatile intermediates in synthetic organic chemistry, since they can be easily converted into compounds with other functional groups such as carboxylic acids, amides, amines, and aldehydes [3]. NaCN and KCN are generally used as the cyanating agents for cyanation of alkyl halides [4]. However, the extremely poisonous nature of these cyanide salts seriously restricts their application from the environmental perspective. Recently, several methods for the cyanation of alkyl halides using trimethylsilyl cyanide ( $\left.\mathrm{Me}_{3} \mathrm{SiCN}\right)$ as the cyanating agent, which is less poisonous, have been developed [5-7]. Unfortunately, the use of $\mathrm{Me}_{3} \mathrm{SiCN}$ is inconvenient as it is expensive, sensitive to moisture, and easily liberates highly poisonous hydrogen cyanide. Recently, an attractive improvement was made by Beller and coworkers $[8,9]$. Nontoxic, inexpensive, and easily handled $\mathrm{K}_{4}\left[\mathrm{Fe}(\mathrm{CN})_{6}\right]$ was, for the first time, introduced as a cyanide source in cyanation reactions [8-10]. Further modifications of the protocol were reported for $\mathrm{Pd}$ - and $\mathrm{Cu}$-catalyzed cyanation of aryl halides with $\mathrm{K}_{4}\left[\mathrm{Fe}(\mathrm{CN})_{6}\right]$ [11-21].

In recent years, considerable attention has been paid to the preparation of heterogeneous Pd catalysts based on nanometer-scale Pd species [22,23]. Pd nanoparticles (PNPs) on a suitable support are recoverable, ligand-free, green catalytic systems with improved catalytic properties [24-31]. In heterogeneous PNP systems, the catalytic properties are improved as a result of the high surface-to-volume ratio, and consequently the large fraction of metal atoms at the surface, and also by strong synergistic interactions between the PNPs and the support [22-31]. Usually, PNP catalysts are prepared from a Pd salt, on a substrate or stabilizer, in the presence of a reducing agent

\footnotetext{
*Corresponding author. Tel: +98-771-4541494; Fax: +98-771-4545188; E-mail: niknam@pgu.ac.ir, khniknam@gmail.com This work was supported by Persian Gulf University. DOI: 10.1016/S1872-2067(12)60532-4 | http://www.sciencedirect.com/science/journal/18722067 | Chin. J. Catal., Vol. 34, No. 4, April 2013
} 


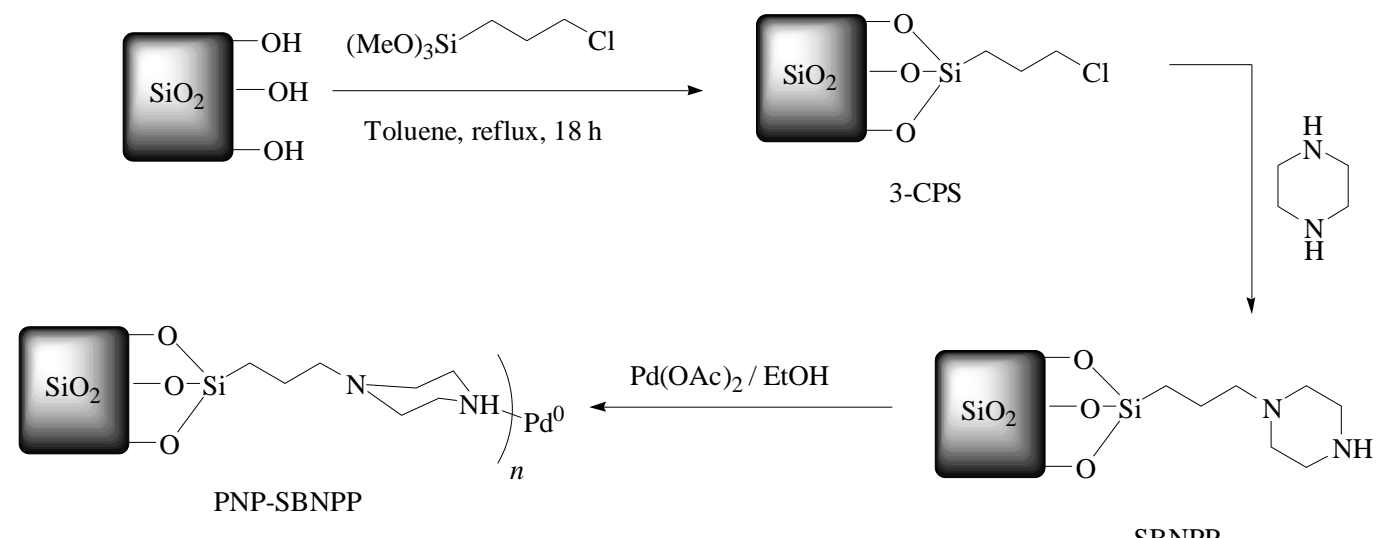

Scheme 1. Synthetic route for preparation of PNP-SBNPP.

$[32,33]$. Steric, electrostatic, and electrosteric factors are responsible for stabilization of the PNPs during their synthesis.

In this paper, we describe the preparation of immobilized PNPs on piperazine-modified silica (PNP-SBNPP) using a three-step process. First, activated silica was reacted with 3-chloropropyltrimethoxysilane in refluxing toluene to produce 3-chloropropylsilica (3-CPS) [34,35]. Second, 3-CPS was treated with piperazine to generate the corresponding substrate [35]. Finally, palladium acetate was reduced on the SBNPP substrate using absolute ethanol as the reducing agent (Scheme 1) $[36,37]$. The piperazines grafted on the silica surface can act as nitrogen ligands to stabilize PNPs, as previously reported for other nitrogen ligands [38-40].

\section{Experimental}

\subsection{General}

Chemicals were purchased from Fluka, Merck, and Aldrich Chemical companies. Infrared spectra were run on a Shimadzu IR-435 spectrometer. ${ }^{1} \mathrm{H}$ and ${ }^{13} \mathrm{C}$ NMR spectra were run on Bruker Avance (500 MHz) and Bruker Ultrashield (400 MHz) spectrometers. Tetramethylsilane was used as the standard and chemical shifts were reported in parts per million (ppm). Melting points were recorded on an SMP1 melting point apparatus in open capillary tubes and are uncorrected. The reaction progress was followed by thin-layer chromatography (TLC) using silica gel SILG/UV 254 plates. 3-CPS was prepared using a previously reported procedure [34].

\subsection{Catalyst preparation}

\subsubsection{Preparation of SBNPP}

To a magnetically stirred mixture of 3-CPS (3 g) in toluene $(110 \mathrm{ml})$, piperazine $(1.3 \mathrm{mmol})$ was added and the mixture was heated at $60-70{ }^{\circ} \mathrm{C}$ in the presence of triethylamine as a proton abstractor, under continuous stirring in a dry nitrogen atmosphere for $48 \mathrm{~h}$. The mixture was filtered and washed with dichloromethane $(10 \mathrm{ml} \times 3)$ and ethanol $(10 \mathrm{ml} \times 3)$. After drying in an oven at $80{ }^{\circ} \mathrm{C}$, SBNPP was obtained as a white powder $(3.4 \mathrm{~g})[34,35]$.

\subsubsection{Preparation of PNP-SBNPP}

To a mixture of SBNPP (1 g) in absolute ethanol $(10 \mathrm{ml})$, palladium acetate $(0.15 \mathrm{~g}, 0.67 \mathrm{mmol})$ was added, and the mixture was stirred for $24 \mathrm{~h}$ at room temperature. The mixture was then filtered and washed with ethanol $(10 \mathrm{ml} \times 3)$. After drying in a vacuum oven at $80{ }^{\circ} \mathrm{C}$, PNP-SBNPP was obtained as a dark solid (1.1 g).

\subsection{General procedure for cyanation reactions}

A mixture of $\mathrm{K}_{4}\left[\mathrm{Fe}(\mathrm{CN})_{6}\right]$ (0.3 mmol), aryl halide (1 mmol), $\mathrm{Na}_{2} \mathrm{CO}_{3}$ (2.5 mmol), PNP-SBNPP (0.05 g, $2.81 \mathrm{~mol} \%$ ), and dimethylformamide (DMF; $2 \mathrm{ml}$ ) was stirred at $120{ }^{\circ} \mathrm{C}$ for the specified time. The reaction was followed using TLC. After completion of the reaction, the mixture was cooled to room temperature and filtered, and the residue was washed with dichloromethane $(10 \mathrm{ml} \times 3)$ to separate the catalyst. Water $(50 \mathrm{ml})$ was added to the organic phase and the dichloromethane was extracted from the water. The organic phase was dried over $\mathrm{Na}_{2} \mathrm{SO}_{4}$. Evaporation of the organic solvent gave the products. For further purification, if needed, the products were passed through a short column of silica gel using $n$-hexane as the eluent. All the products are known compounds and were compared with authentic samples.

\section{Results and discussion}

Transmission electron microscopy (TEM) images of the PNP-SBNPP catalyst (Fig. 1) show that PNPs with a near spher-
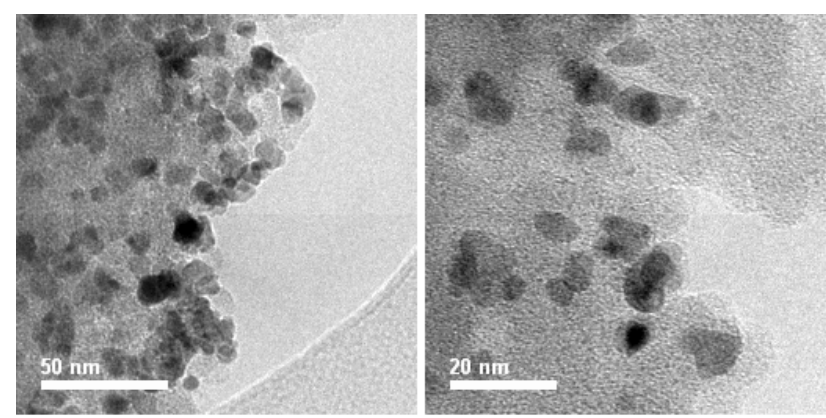

Fig. 1. TEM images of PNPs on SBNPP support. 


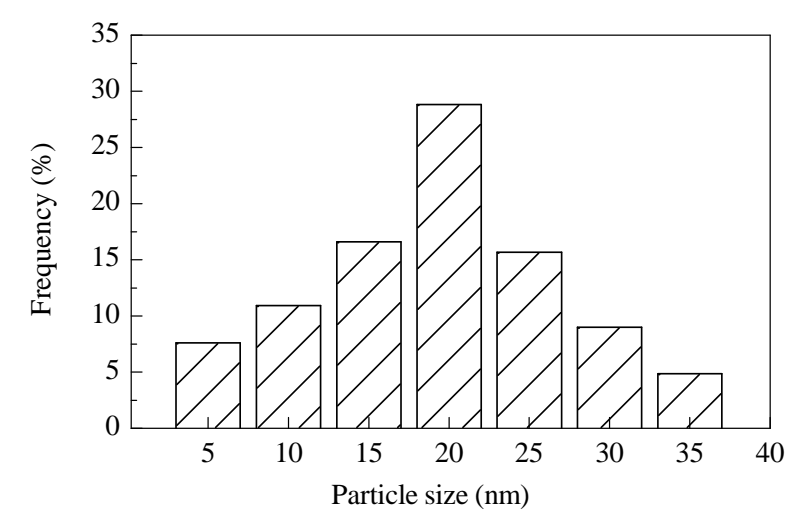

Fig. 2. Histogram showing size distribution of PNPs on SBNPP substrate.

ical morphology are assembled on the SBNPP support with relatively good monodispersity. A histogram showing the size distribution of the PNPs on the SBNPP substrate is shown in Fig. 2, based on the data obtained from the TEM images. The average size of PNPs in the Pd-SBNPP catalyst was $20 \mathrm{~nm}$ (Fig. 2).

The microscopic features of the catalyst were observed using scanning electron microscopy (SEM; Fig. 3). In this figure, we can see the morphology of the silica substrate. It can be seen that PNPs with a near spherical morphology are well immobilized on the SBNPP substrate.

The X-ray diffraction (XRD) pattern in Fig. 4 shows the crystalline structure of the PNP-SBNPP catalyst. The XRD pattern of the PNP-SBNPP catalyst also shows PNPs on the silica surface. The strongest peaks of the XRD pattern correspond to

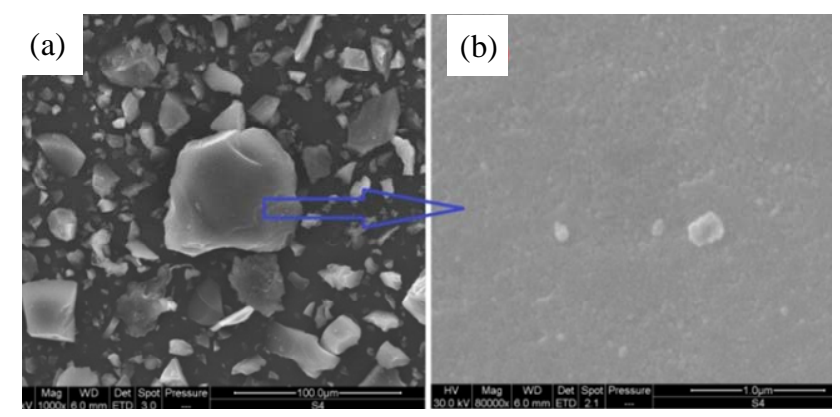

Fig. 3. SEM images of PNP-SBNPP.

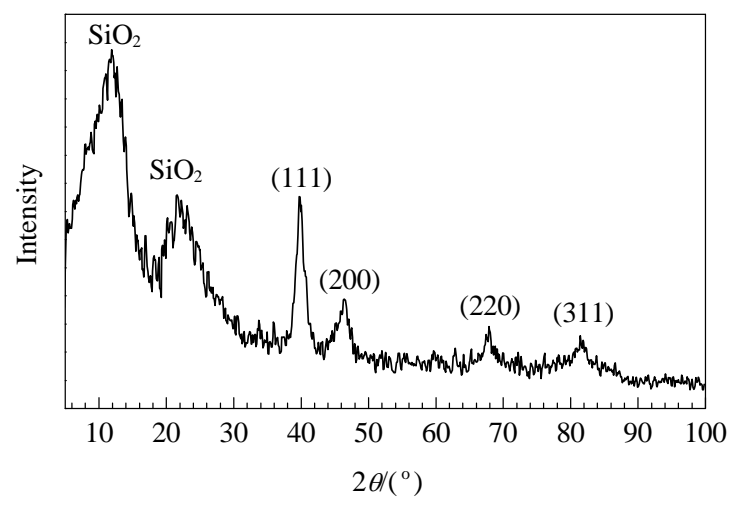

Fig. 4. XRD pattern of PNP-SBNPP.

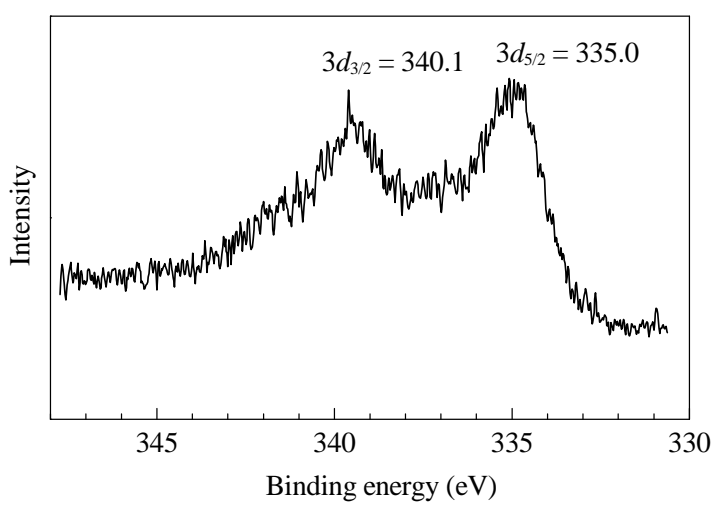

Fig. 5. XPS profile of PNP-SBNPP.

$\mathrm{SiO}_{2}$, and the other peaks are indexed as the (111), (200), (220), and (311) planes of the PNPs [28,30].

Figure 5 shows the X-ray photoelectron spectrum (XPS) of the $\mathrm{Pd}(3 d)$ envelope, confirming the presence of metallic $\mathrm{Pd}$ particles. XPS $\operatorname{Pd}\left(3 d_{5 / 2}\right)$ and $\operatorname{Pd}\left(3 d_{3 / 2}\right)$ peaks were observed at binding energies of 335 and $340.1 \mathrm{eV}$, respectively. These binding energies are similar to those reported in the literature for Pd metal [30,41].

To confirm the Pd content, the supported catalyst was treated with concentrated $\mathrm{HCl}$ and $\mathrm{HNO}_{3}$ to digest the Pd species and then analyzed using inductively coupled plasma atomic emission spectroscopy. The Pd content of PNP-SBNPP was determined to be $\delta=60.0(60.0 \mathrm{mg} / \mathrm{L}=6.0 \%, \mathrm{w} / \mathrm{w})$.

The reaction of iodobenzene with $\mathrm{K}_{4}\left[\mathrm{Fe}(\mathrm{CN})_{6}\right]$ was studied as a model reaction and the catalytic loading of PNP-SBNPP and the reaction conditions were screened. The optimized conditions were aryl halide ( $1 \mathrm{mmol}), \mathrm{K}_{4}\left[\mathrm{Fe}(\mathrm{CN})_{6}\right](0.3 \mathrm{mmol})$, $\mathrm{Na}_{2} \mathrm{CO}_{3}$ (2.5 mmol), and PNP-SBNPP (0.05 g, $\left.2.81 \mathrm{~mol} \%\right)$ in 2 $\mathrm{ml}$ of DMF solvent at $120^{\circ} \mathrm{C}$ (Scheme 2).

The system was extended to the reaction of $\mathrm{K}_{4}\left[\mathrm{Fe}(\mathrm{CN})_{6}\right]$ with other aryl halides (Table 1). The cyanation of iodobenzene with $\mathrm{K}_{4}\left[\mathrm{Fe}(\mathrm{CN})_{6}\right]$ provided the nitrile in $85 \%$ yield (Table 1, entry 2). Bromo- and chloro-benzene treated with $\mathrm{K}_{4}\left[\mathrm{Fe}(\mathrm{CN})_{6}\right]$ respectively provided benzonitrile in $70 \%$ and $51 \%$ yields (Table 1, entries 4 and 5). 3-Bromopyridine and 3-chloropyridine were also successfully cyanated, providing a useful way of introducing a cyanide group on a pyridine ring (Table 1, entries 7 and 8). Cyanation of aryl halides in the presence of different functionalities such as hydroxyl, amine, and carbonyl was also achieved using the present catalytic system (Table 1, entries 6, 10-12).

The possibility of recycling the catalyst was examined using the reaction of iodobenzene with $\mathrm{K}_{4}\left[\mathrm{Fe}(\mathrm{CN})_{6}\right]$ under the opti-

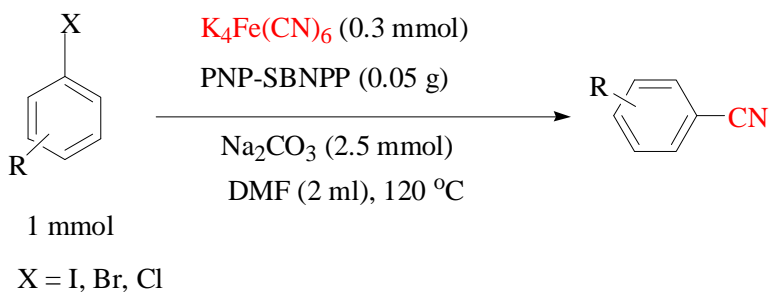

Scheme 2. PNP-SBNPP-catalyzed cyanation reaction. 
Table 1

PNP-SBNPP-catalyzed cyanation reactions.

\begin{tabular}{|c|c|c|c|c|c|c|c|}
\hline Entry & Aryl halide & Product & Catalyst amount $(\mathrm{g})$ & Time (h) & Yield* (\%) & TON & TOF \\
\hline 1 & & & 0.03 & 6 & 81 & 47.93 & 7.98 \\
\hline 2 & & & 0.05 & 5 & 85 & 30.24 & 6.04 \\
\hline 3 & & & 0.075 & 4 & 90 & 21.32 & 5.33 \\
\hline 4 & & & 0.05 & 8 & 70 & 24.91 & 3.11 \\
\hline 5 & & & 0.05 & 16 & 51 & 18.15 & 1.13 \\
\hline 6 & & & 0.05 & 10 & 72 & 25.62 & 2.56 \\
\hline 7 & & & 0.05 & 7 & 79 & 28.11 & 4.01 \\
\hline 8 & & & 0.05 & 16 & 57 & 20.28 & 1.27 \\
\hline 9 & & & 0.05 & 8 & 78 & 27.76 & 3.47 \\
\hline 10 & & & 0.05 & 16 & 63 & 22.42 & 1.40 \\
\hline 11 & $\mathrm{Br}$ & & 0.075 & 12 & 65 & 15.40 & 1.28 \\
\hline 12 & & & 0.075 & 5 & 79 & 18.72 & 3.74 \\
\hline
\end{tabular}

Reaction conditions: aryl halide $(1 \mathrm{mmol}), \mathrm{K}_{4} \mathrm{Fe}(\mathrm{CN})_{6}(0.3 \mathrm{mmol}), \mathrm{Na}_{2} \mathrm{CO}_{3}(2.5 \mathrm{mmol})$, DMF $(2 \mathrm{ml})$ at $120^{\circ} \mathrm{C} .{ }^{*}$ Isolated yield.

mized conditions. Upon completion, the reaction mixture was filtered and the catalyst was washed with dichloromethane. The recycled catalyst could be reused four times without any treatment (Fig. 6).

\section{Conclusions}

In conclusion, this work shows that PNPs can be stabilized efficiently by a SBNPP substrate. These materials can be prepared, using a simple procedure, from commercially available and relatively cheap starting materials. The PNP-SBNPP cata-

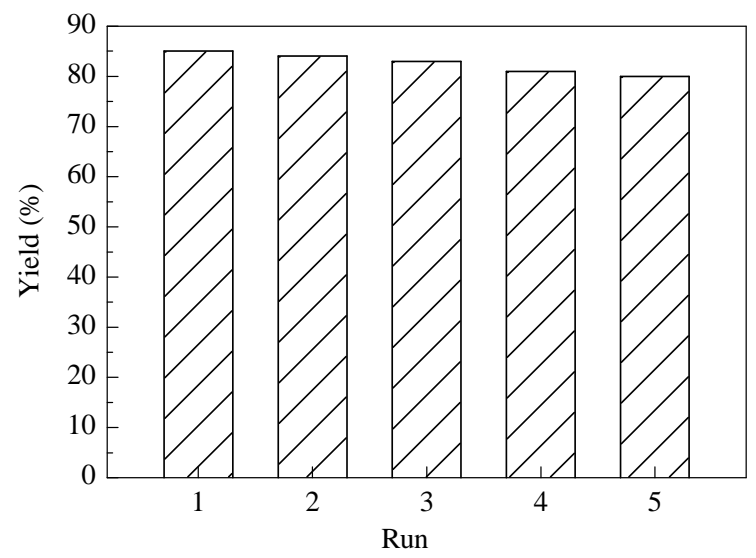

Fig. 6. Recyclability of PNP-SBNPP in reaction of iodobenzene $(1 \mathrm{mmol})$ $\mathrm{K}_{4}\left[\mathrm{Fe}(\mathrm{CN})_{6}\right](0.3 \mathrm{mmol}), \mathrm{Na}_{2} \mathrm{CO}_{3}(2.5 \mathrm{mmol})$, and $\mathrm{DMF}(2 \mathrm{ml})$ at $120^{\circ} \mathrm{C}$ for $5 \mathrm{~h}$. lyst efficiently catalyzed the cyanation reactions of aryl halides, with good to high yields. This catalyst could also be recovered and reused several times without noticeable loss of activity.

\section{Acknowledgments}

We thank the Persian Gulf University Research Council for partial support of this work. We also thank the School of Chemistry, Manchester University, for running NMR, TEM, and SEM.

\section{References}

[1] Kleemann A, Engel J, Kutscher B, Reichert D. Pharmaceutical Subtances: Syntheses, Patents, Applications. 4th Ed. Stuttgart: Georg Thieme, 2001

[2] Collier S J, Langer P. Sci Synth, 2004, 19: 403

[3] Rappoport Z. Chemistry of the Cyano Group. 1st Ed. London: John Wiley \& Sons, 1970

[4] Chidambaram M, Sonavane S U, De La Zerda J, Sasson Y. Tetrahedron, 2007, 63: 7696

[5] Kitano Y, Manoda T, Miura T, Chiba K, Tada M. Synthesis, 2006, 405

[6] Reddy C R, Madhavi P P, Reddy A S. Tetrahedron Lett, 2007, 48: 7169

[7] Yabe 0, Mizufune H, Ikemoto T. Synlett, 2009: 1291

[8] Schareina T, Zapf A, Mägerlein W, Müller N, Beller M. Tetrahedron Lett, 2007, 48: 1087

[9] Schareina T, Jackstell R, Schulz T, Zapf A, Cotte A, Gotta M, Beller M. Adv Synth Catal, 2009, 351: 643

[10] Ren Y L, Dong C H, Zhao S, Sun Y D, Wang J J, Ma J Y, Hou C D. 


\section{Graphical Abstract}

Chin. J. Catal., 2013, 34: 718-722 doi: 10.1016/S1872-2067(12)60532-4

Silica-functionalized $\boldsymbol{N}$-propylpiperazine for immobilization of palladium nanoparticles as efficient heterogeneous catalyst for cyanation reactions

Khodabakhsh NIKNAM*, Abdollah DERIS, Farhad PANAHI

Persian Gulf University, Iran

A simple and efficient procedure for the cyanation of aryl halides with $\mathrm{K}_{4}\left[\mathrm{Fe}(\mathrm{CN})_{6}\right]$ in the presence of $\mathrm{Pd}$ nanoparticles on silica-bonded N-propylpiperazine (PNP-SBNPP) is described. This heterogeneous catalyst could be recycled several times without appreciable loss of catalytic activity.

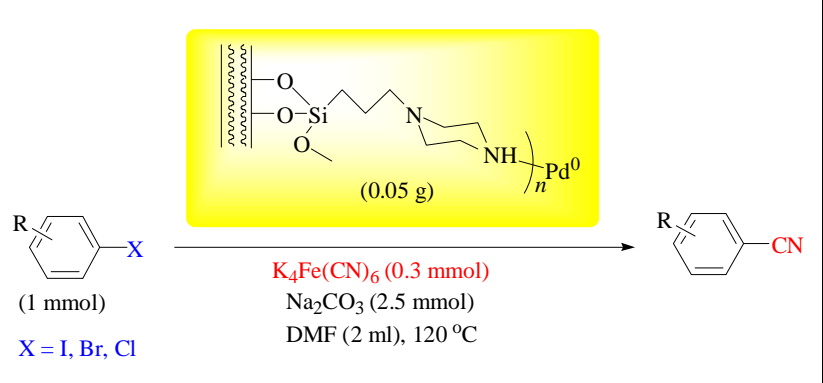

Tetrahedron Lett, 2012, 53: 2825

[11] Chattopadhyay K, Dey R, Ranu B C. Tetrahedron Lett, 2009, 50: 3164

[12] De Blase C, Leadbeater N E. Tetrahedron, 2010, 66: 1098

[13] Zhang J L, Chen X R, Hu T J, Zhang Y, Xu K L, Yu Y P, Huang J. Catal Lett, 2010, 139: 56

[14] Shevlin M. Tetrahedron Lett, 2010, 51: 4833

[15] Hajipour A R, Karami K, Tavakoli G, Pirisedigh A. J Organomet Chem, 2011, 696: 819

[16] Shim Y J, Lee H J, Park S. J Organomet Chem, 2012, 696: 4173

[17] Kianmehr E, Ghanbari M, Faghih N, Rominger F. Tetrahedron Lett, 2012, 53: 1900

[18] Ren Y L, Liu Z F, He S B, Zhao S, Wang J J, Niu R Q Yin W P. Org Process Res Dev, 2009, 13: 764

[19] Shareina T, Zapf A, Cotte A, Muller N, Beller M. Synthesis, 2008: 3351

[20] Sergeev A G, Schulz T, Torborg C, Spamenberg A, Neumann H, Beller M. Angew Chem, Int Ed, 2009, 48: 7595

[21] Hajipour A R, Karami K, Pirisedigh A. Appl Organometal Chem, 2010, 24: 454

[22] Moussa S, Siamaki A R, Gupton B F, El-Shall M S. ACS Catal, 2012, 2: 145

[23] Cheng J S, Zhang G C, Du J, Tang L H, Xu J Y, Li J H. J Mater Chem, 2011, 21: 3485

[24] Karimi B, Abedi S, Clark J H, Budarin V. Angew Chem, Int Ed, 2006, 45: 4776

[25] Polshettiwar V, Len C, Fihri A. Coord Chem Rev, 2009, 253: 2599

[26] Demel J, Cejka J, Stepnicka P. J Mol Catal A, 2010, 329: 13
[27] Astruc D. Tetrahedron: Asymmetry, 2010, 21: 1041

[28] Firouzabadi H, Iranpoor N, Gholinejad M. J Organomet Chem, 2010, 695: 2093

[29] Corma A, Iborra S, Xamena F X L I, Monton R, Calvino J J, Prestipino C. J Phys Chem C, 2010, 114: 8828

[30] Niknam K, Gharavi A, Hormozi-Nezhad M R, Panahi F, Sharbati M T. Synthesis, 2011: 1609

[31] Khalafi-Nezhad A, Panahi F. Green Chem, 2011, 13: 2408

[32] Richard R. Surface and Nanomolecular Catalysis. London: Taylor \& Francis, 2006

[33] Burda C, Chen X, Narayanan R, El-Sayed M A. Chem Rev, 2005, 105 : 1025

[34] Niknam K, Deris A, Naeimi F, Majleci F. Tetrahedron Lett, 2011, 52: 4642

[35] Dey R K, Patnaik T, Singh V K, Swain S K, Airoldi C. Appl Surf Sci, 2009, 255: 8176

[36] Horváth A, Beck A, Sárkány A, Guczi L. Solid State Ionics, 2002, 148: 219

[37] Wang L C, Huang C Y, Chang C Y, Lin W C, Chao K J. Microporous Mesoporous Mater, 2008, 110: 451

[38] van Laren M W, Duin M A, Klerk C, Naglia M, Rogolino D, Pelaratti P, Bacchi A, Pelizzi C, Elsevier C J. Organometallics, 2002, 21: 1546

[39] Kluwer A M, Elsevier C J, Bühl M, Lutz M, Spek A L. Angew Chem, Int $E d, 2003,42: 3501$

[40] van Asselt R, Elsevier C J. Tetrahedron, 1994, 50: 323

[41] Moulder J F, Stickle W F, Sobol P E, Bomben K D. Handbook of X-ray Photoelectron Spectroscopy. USA: Physical Electronics Inc, 1995. 118-119 